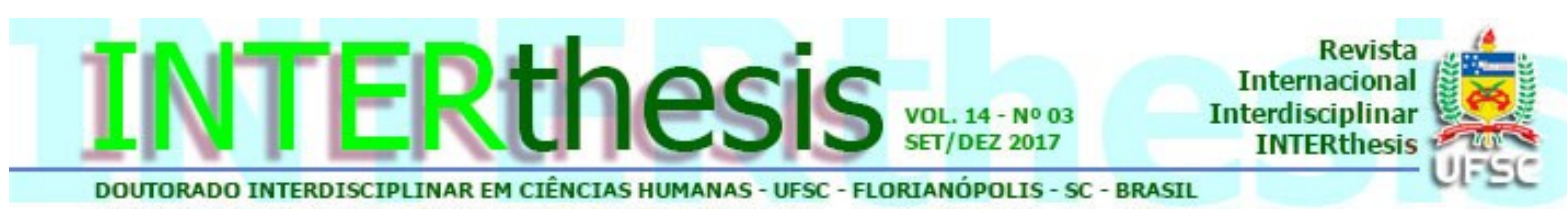

\title{
POLÍTICAS PÚBLICAS E EDUCAÇÃo SEXUAL: PERCEPÇÕES DE PROFISSIONAIS DA SAÚDE E DA EDUCAÇÃO
}

\author{
Priscila Mugnai Vieira ${ }^{1}$ \\ Thelma Simões Matsukura ${ }^{2}$ \\ Camila Mugnai Vieira ${ }^{3}$
}

\section{Resumo:}

Ações de promoção, proteção e recuperação da saúde integral voltadas à sexualidade na adolescência são preconizadas por diversas Políticas Públicas, no entanto, para o avanço de ações neste campo, desafios e limites têm sido investigados. Nesta pesquisa objetivou-se identificar, sob a ótica de profissionais inseridos em serviços públicos de Saúde e Educação, os avanços e desafios implicados nas Políticas Públicas vinculadas à adolescência e à Educação Sexual. Tratou-se de um estudo de abordagem qualitativa, no qual 20 profissionais do serviço público de Saúde e Educação de um município de grande porte do interior de São Paulo foram entrevistados. Os resultados de ambos os setores revelaram a percepção de que as Políticas Públicas vinculadas à Educação Sexual e à adolescência trazem contribuições para as práticas, embora apresentem fragilidades. Como contribuições, destacaram-se: os subsídios e o respaldo legais para a execução das práticas. Dentre as fragilidades reveladas têm-se as propostas descontextualizadas, falta de suporte prático e desconhecimento dos profissionais sobre as políticas. As informações apreendidas contribuem para a identificação de potencialidades e lacunas que podem ser utilizadas como ferramentas para a avaliação e elaboração das políticas. Nesta direção, somam-se elementos para a implementação do que está previsto pelas políticas públicas na realidade das práticas de Educação Sexual.

Palavras-chave: Políticas Públicas. Saúde Coletiva. Sexualidade. Educação Sexual. Adolescentes.

\section{INTRODUÇÃO}

Atualmente ações de promoção, proteção e recuperação da saúde integral, voltadas à sexualidade na adolescência, estão preconizadas por diversas Políticas

\footnotetext{
${ }^{1}$ Mestranda em Terapia Ocupacional pela Universidade Federal de São Carlos. Articuladora Regional do Programa São Paulo pela Primeiríssima Infância (parceria entre Secretaria Estadual da Saúde, Fundação Maria Cecília Souto Vidigal e municípios paulistas) em São Carlos, SP, Brasil. E-mail: psicopri@gmail.com

${ }^{2}$ Doutora em Saúde Mental pela Universidade de São Paulo. Pós-doutorado em Saúde Pública pela mesma universidade. Professora Associada no Departamento de Terapia Ocupacional da Universidade Federal de São Carlos. Docente do Programa de Pós graduação em Terapia Ocupacional e Educação Especial da mesma universidade, São Carlos, Brasil. E-mail: thelma@ufscar.br

${ }^{3}$ Doutora em Educação pela UNESP de Marília. Professora na Faculdade de Medicina de Marília, SP, Brasil. E-mail:camilamugnai@gmail.com
} 
Públicas. O objetivo principal destes documentos é contribuir positivamente para a qualidade de vida na adolescência, de modo a reduzir diversas situações de risco e vulnerabilidades relacionadas à sexualidade.

A conduta sexual dos indivíduos passou a ser objeto de análise no campo da medicina, das atividades pedagógicas, demográficas, políticas e governamentais e, com o objetivo de dar maior enfoque às questões de sexualidade na adolescência, tais campos do saber têm se debruçado sobre essa temática a fim de garantir a saúde individual e coletiva da sociedade (ALTMANN, 2007).

De acordo com Paiva et. al. (2008), ao abordar sobre questões de iniciação da vida sexual e do uso de preservativos, destaca-se o crescente esforço brasileiro, desde 1990, para se pensar Políticas Públicas vinculadas à Educação Sexual de crianças, adolescentes e jovens especialmente no âmbito escolar.

O Estatuto da Criança e do Adolescente (ECA) mostrou-se uma Política Pública voltada para a infância e para adolescência de significativa importância em múltiplos sentidos, principalmente no que se refere ao reconhecimento de que crianças e adolescentes devem ser prioridade absoluta, bem como são sujeitos que têm direitos e responsabilidades. Especificamente no artigo 11 é ressaltado sobre odireito de crianças e adolescentes à saúde integral (BRASIL, 1990b). Neste sentido, o acesso aos diversos serviços de saúde, dentre eles, aqueles relacionados aos cuidados com a sexualidade, é garantido legalmente aos adolescentes.

De acordo com o estudo de Sfair (2012), a predominância de documentos, programas e projetos públicos que se debruçam sobre as práticas educativas em sexualidade na adolescência são provenientes do Ministério da Saúde. A autora aponta que estes documentos, em sua maioria, focam subsídios teóricos e práticos para os profissionais que desenvolvem as práticas vinculadas à Educação Sexual.

O programa de Planejamento Familiar, ainda que não seja uma Política Pública exclusiva para a adolescência, inclui ações de prevenção nos serviços de saúde voltadas às mulheres nesta etapa do desenvolvimento. Este programa inclui a abordagem sobre os métodos contraceptivos, gravidez, pré-natal, parto e outras temáticas que se relacionam com a anticoncepção (BRASIL, 1996b).

Em 1996 foi criado pelo Ministério da Saúde, o Programa "Saúde para Adolescentes" (PROSAD). Esta política apresenta estratégias de intervenção e cuidados para adolescentes que tem por objetivo reduzir questões de risco e R. Inter. Interdisc. INTERthesis, Florianópolis, v.14, n.3, p. 69-87 Set.-Dez. 2017 
vulnerabilidades. Antecede as demais Políticas Públicas Nacionais que, com objetivos similares, foram desenvolvidas para garantir o cuidado integral à saúde dos adolescentes, com destaque às questões relativas à sexualidade (BRASIL, 1996a).

Em 2007 foi divulgada a versão preliminar da Política de Atenção Integral à Saúde de Adolescentes e Jovens (BRASIL, 2007b). O documento destaca diversos fatores determinantes que repercutem nas condições de saúde na adolescência e destaca sobre a saúde sexual e reprodutiva. Reconhece-se que esta questão deve ser priorizada nas práticas de cuidado com esta população, uma vez que é considerada a dimensão de maior vulnerabilidade nesta etapa do desenvolvimento.

Neste mesmo ano, de 2007, foi lançado o Marco Teórico Referencial da Saúde Sexual e Reprodutiva de Adolescentes e Jovens (BRASIL, 2007a). Este documento discute questões teóricas sobre a sexualidade na adolescência e inclui os aspectos legais que reconhecem os direitos sexuais e reprodutivos da população adolescente.

Ainda em 2007, foi lançado o Programa Saúde nas Escolas (PSE) (BRASIL, 2007c), uma parceria entre os Ministérios da Educação e da Saúde. Este programa apresenta uma perspectiva intersetorial de atuação entre os setores da Saúde e da Educação frente a diversas temáticas vinculadas à saúde integral da criança e do adolescente, dentre elas, questões relacionadas à sexualidade.

Em 2008, na Cidade do México, em conferência sobre a Síndrome da Imunodeficiência Adquirida (AIDS), voltada aos ministros da Educação e da Saúde dos países da América Latina e Caribe, foi assinada a Declaração "Prevenir com Educação", onde foram estabelecidas metas relativas às práticas de educação em saúde e sexualidade para adolescentes e jovens até o ano de 2015, que consistem em reduzir em $75 \%$ o número de escolas que não tem institucionalizada a Educação Sexual e reduzir em $50 \%$ de jovens e adolescentes que carecem da cobertura de serviços para atender suas necessidades de saúde (GOMES; VIEIRA, 2010).

Em 2013 foi produzido o Caderno de Atenção Básica sobre a Saúde Sexual e Reprodutiva de Adolescentes e Jovens (BRASIL, 2013). Este documento oferece subsídios e orientação voltados aos profissionais deste nível de atenção à saúde, sobre práticas de cuidado em saúde e sexualidade. Do mesmo modo, em seus conteúdos retoma sobre as dimensões legais que respaldam o trabalho de prevenção de agravos e promoção à saúde sexual e reprodutiva com adolescentes.

R. Inter. Interdisc. INTERthesis, Florianópolis, v.14, n.3, p. 69-87 Set.-Dez. 2017 
As Políticas citadas anteriormente são algumas dentre muitas outras do Ministério da Saúde, que merecem destaque. Tais documentos públicos se configuram como eixos norteadores para as práticas vinculadas à Educação Sexual realizadas nos serviços de saúde. Pode reconhecer-se, a partir dessas Políticas Públicas, a responsabilidade, legitimidade e importância de se garantir a abordagem da Educação Sexual na adolescência nos serviços de saúde.

Na área da Educação, desde a Lei de Diretrizes e Bases (LDB) (BRASIL, 1996b), se discute a transversalidade de temáticas, entendidas como questões relevantes que recortam a vida dos sujeitos e que não devem estar relacionadas exclusivamente a determinadas disciplinas e conteúdos curriculares.

Em 1997 foram elaborados os Parâmetros Curriculares Nacionais (PCN) e, assim como a LDB, o documento destaca a questão da transversalidade. A proposta de transversalidade neste documento, com a referência aos temas transversais que se mostram relacionados às questões sociais, ressalta sobre a abordagem das questões de sexualidade nas diversas disciplinas e não somente nas convencionais, vinculadas às Ciências Naturais (BRASIL, 1997).

Os PCN, no capítulo denominado "Orientação Sexual", abordam sobre temáticas relacionadas à sexualidade a serem trabalhadas nas escolas. Este documento está organizado e dividido em três seções: corpo e matriz da sexualidade; relações de gênero e prevenção das DST e AIDS (BRASIL, 1997).

Pautado nas premissas dos direitos humanos e da cidadania, atreladas ao respeito às diversidades sexuais e de gênero, os $\mathrm{PCN}$ ressaltam a importância da abordagem da sexualidade nas escolas, e legitimam a execução das práticas de Educação Sexual no espaço escolar (BRASIL, 1997). Apesar disso, Silva (2007) afirma que autores apontam críticas aos PCN sobre sua abordagem das questões de gênero, pois é considerada restrita, uma vez que apresenta as diferenças dos gêneros predominantemente focadas na genitalidade, ou seja, nas questões biológicas. Afora tais posicionamentos críticos, de acordo com os princípios dos PCN, a escola tem como responsabilidade prezar pela saúde de seus alunos e, sobretudo, formar cidadãos conscientes, críticos e responsáveis, tanto em uma dimensão individual quanto social e coletiva (BRASIL, 1997).

Com relação aos PCN, Nardi e Quartiero (2012) afirmam que permanece um desconhecimento por parte dos profissionais da área da Educação sobre este R. Inter. Interdisc. INTERthesis, Florianópolis, v.14, n.3, p. 69-87 Set.-Dez. 2017 
documento. Esta lacuna existente em relação aos PCN, somada a não obrigatoriedade de execução de práticas de intervenção, pode justificar o fato de muitas instituições de educação não desenvolverem trabalhos de Educação Sexual em uma perspectiva de transversalidade. A partir deste enfoque, ao invés de a sexualidade ser abordada de forma a recortar as diversas disciplinas, as intervenções passam a ocorrer de modo restrito aos currículos, bem como de forma esporádica e/ou não sistematizada (SILVA; MEGID-NETO, 2006; FONTES, 2008).

Sobre as abordagens curriculares da temática da sexualidade, o Programa Nacional do Livro Didático (PNLD) e a Política Nacional do Livro Didático para o Ensino Médio (PNLEM) são responsáveis pela elaboração dos materiais didáticos, livros e dicionários, a serem utilizados no ensino público (RIOS; SANTOS, 2008). Temáticas são incluídas nos conteúdos destes materiais com o objetivo de garantir uma educação mais integral e cidadã, tais como mudanças e contextos atuais de família, diversidades étnicas, raciais, sexuais, dentre outras questões que ainda são perpassadas por valores morais cristalizados e que necessitam ser alvo de problematização e reflexão (FONTES, 2008).

Deste modo, apesar dos avanços no sentido de reconhecimento sobre a importância da inclusão de temas diferenciados nos conteúdos curriculares, estudos ainda identificam que permanecem lacunas com relação a determinadas temáticas em sexualidade, mantendo-se o foco nos aspectos biológicos e reprodutivos da sexualidade (RIOS; SANTOS, 2008; FONTES, 2008; NARDI, 2008).

Conforme exposto, inúmeras iniciativas são pensadas com o objetivo de garantir que questões de sexualidade sejam trabalhadas junto à população adolescente. Para além da existência destes documentos e Políticas Públicas, ressalta-se sobre as possibilidades de aplicação e efetivação na realidade concreta. É reconhecido que no Brasil permanece um significativo distanciamento entre as chamadas "lei no livro" e "lei na ação" (NARDI, 2008). Somado a esta questão, destaca-se a não obrigatoriedade de utilização de documentos, conforme explicitado anteriormente sobre os PCN (SILVA; MEGID-NETO, 2006).

As Políticas Públicas devem balizar e dar subsídios às práticas, embora a sua pouca utilização e/ou desconhecimento ainda resulte em ações marcadas por valores pessoais, muitas vezes moralizantes, por parte daqueles que executam a Educação Sexual (SILVA; MEGID-NETO, 2006; FONTES, 2008).

R. Inter. Interdisc. INTERthesis, Florianópolis, v.14, n.3, p. 69-87 Set.-Dez. 2017 
Assim, a partir do reconhecimento de possíveis desafios para a efetivação das Políticas Públicas nas práticas, bem como de que tais políticas devem oferecer suporte e embasamento para a execução das ações, o presente estudo objetivou identificar, sob a ótica de profissionais inseridos em serviços públicos de Saúde e Educação, os avanços e desafios implicados nas Políticas Públicas vinculadas à adolescência e à Educação Sexual.

\section{MÉTODO}

Tratou-se de um estudo de abordagem qualitativa, vinculado à pesquisa mais ampla desenvolvida junto a um Programa de Pós-Graduação em uma Universidade Federal, da qual participaram 20 profissionais do serviço público de um município de grande porte do interior de São Paulo, 10 vinculados à Estratégia de Saúde da Família (ESF) e 10 professores que atuavam no ciclo II do Ensino Fundamental de escolas estaduais.

Todas as escolas estaduais do município que atendem ao ciclo II e todas as Unidades de Saúde da Família foram convidadas a participar do estudo. No total de 21 escolas, 10 aceitaram e participaram do estudo e, no setor da Saúde, de um total de 17 Unidades, 10 participaram. Em ambos os setores (Educação e Saúde) eram indicados pela gestão do serviço os profissionais que estivessem desenvolvendo práticas vinculadas à Educação Sexual com adolescentes.

Foram realizadas entrevistas semidirigidas individuais a partir de um roteiro de entrevista semiestruturado, com adequações após aplicação de estudo piloto em uma escola e uma Unidade de Saúde e avaliação de quatro juízes, especialistas da área. A metodologia de análise dos dados foi a Análise Temática (BARDIN, 2009).

\section{RESULTADOS E DISCUSSÃO}

Foram identificados os conteúdos das entrevistas relacionados à percepção dos profissionais sobre as Políticas Públicas provenientes dos Ministérios da Saúde e da Educação vinculadas à prática da Educação Sexual. Em ambos os setores foram identificadas duas categorias de análise: "Contribuições e Fragilidades". Aponta-se que para cada categoria de análise foram identificados seus respectivos eixos temáticos, conforme a Tabela 1. 
Tabela 1: Políticas Públicas e as Práticas de Educação Sexual

\begin{tabular}{|c|c|c|}
\hline \multirow[t]{2}{*}{ CATEGORIAS DE ANÁLISE } & \multicolumn{2}{|c|}{ EIXOS TEMÁTICOS } \\
\hline & Educação & Saúde \\
\hline Contribuições & $\begin{array}{ll}\text { 1. Subsídios teóricos e } \\
\text { práticos } \\
\text { 2. Respaldo legal } \\
\text { 3. Garantia de } \\
\text { execução }\end{array}$ & $\begin{array}{ll}\text { 1. Subsídios teóricos } \\
\text { 2. Garantia de execução }\end{array}$ \\
\hline Fragilidades & 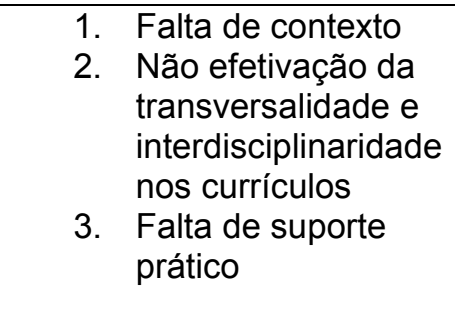 & $\begin{array}{ll}\text { 1. } & \text { Falta de suporte } \\
\text { prático } \\
\text { 2. Ausência de } \\
\text { documentos } \\
\text { 3. Necessidade de maior } \\
\text { entendimento e } \\
\text { aproximação dos } \\
\text { profissionais das PP }\end{array}$ \\
\hline
\end{tabular}

Fonte: Elaborado pelas autoras

\subsection{SETOR DA EDUCAÇÃO}

Com relação à categoria de análise "Contribuições", o entendimento de que as Políticas Públicas vinculadas à Educação Sexual contribuem para as práticas esteve relacionado à compreensão de que elas oferecem subsídios para as ações nas escolas. Verifica-se que, apesar do reconhecimento de que as Políticas Públicas oferecem subsídios, não existe clareza sobre quais são estas contribuições e, possivelmente, sobre como implementá-las.

Observa-se que a existência das Políticas não garante sua utilização, bem como não oferece necessariamente, de acordo com os resultados aqui apresentados, subsídios concretos e práticos para sua efetivação na realidade das práticas. Além disso, a falta de clareza sobre os subsídios que as Políticas oferecem pode estar relacionada à necessidade de haver maior proximidade dos professores em relação aos documentos públicos, conforme se verifica no depoimento:

Eu acho que eles contribuem sim. Eu acho que na verdade são documentos que deveriam ficar muito mais nas mãos, ao alcance dos professores na escola. Eles contribuem com a prática dos professores na escola, mas eles não estão muito à mão para os professores lerem e discutirem juntos. (E3)

Os princípios e diretrizes norteadores das práticas de Educação Sexual na escola estão contidos em documentos públicos da Educação, como nos PCN (BRASIL, 1997) e Projetos estaduais como a "Prevenção também se Ensina" e demais documentos voltados às temáticas mais específicas em sexualidade como a 
cartilha "Diversidade Sexual na Educação: problematizações sobre a homofobia nas escolas" (BRASIL, 2009a), dentre outros.

Em conformidade aos resultados deste estudo, a literatura aponta que embora seja reconhecida a legitimidade e importância dos PCN para as práticas de Educação Sexual, observa-se que permanece um desconhecimento por parte dos profissionais que se encontram na prática sobre este documento (NARDI; QUARTIERO, 2012). Ressalta-se que tanto os PCN quanto os demais documentos públicos vinculados à Educação Sexual servem de apoio para as práticas, no entanto sua utilização não é obrigatória (SILVA; MEGID-NETO, 2006). Ou seja, embora os PCN sustentem uma concepção e abordagem ampliada da sexualidade e das práticas de Educação Sexual, em função da não obrigatoriedade da utilização deste documento nas escolas, as práticas permanecem balizadas pelos conteúdos dos currículos que, em sua maioria, estão restritos às questões biológicas, bem como às disciplinas das áreas de Ciências (FONTES, 2008).

Os PCN ainda sugerem que a sexualidade se trata de um tema transversal e que pode ser trabalhado nas demais disciplinas e interdisciplinarmente (BRASIL, 1997). Em conformidade com o que se é preconizado, verificou-se nos resultados a importância da superação do modelo disciplinar e efetivação da transversalidade nas práticas, conforme se observa no relato a seguir:

\footnotetext{
Eu acho que dentro de uma Unidade de Educação, eu acho que todas as áreas deviam abordar. Eu acho que num texto de português, língua portuguesa às vezes aparece e seria uma oportunidade de esclarecer. Não é mandar procurar no dicionário. (E6)
}

Para além do reconhecimento da necessidade de superação das lógicas disciplinares das práticas de Educação Sexual, assim como é colocado pelos PCN e reafirmado nos resultados, reflete-se novamente sobre quais são as reais condições que esta Política, bem como os demais documentos públicos, o que oferecem para que os profissionais e serviços possam concretizá-las nas práticas.

Ainda com relação a não efetivação das Políticas, a cartilha "Diversidade Sexual na Educação: problematizações sobre a homofobia nas escolas", já citada, ao abordar a temática do combate à homofobia, convida a escola, a exercer seu papel social no sentido de superar a reprodução de lógicas perversas de opressão e reforço das desigualdades (BRASIL, 2009a). Deste modo, a não obrigatoriedade, desconhecimento ou desuso deste documento para embasar as ações, faz com que

R. Inter. Interdisc. INTERthesis, Florianópolis, v.14, n.3, p. 69-87 Set.-Dez. 2017 
as abordagens vinculadas à diversidade sexual fiquem à revelia dos valores pessoais, morais e subjetivos dos profissionais (NARDI; QUARTIERO, 2012).

Com relação às fragilidades, outros pontos foram destacados no setor da Educação, como o distanciamento das Políticas da realidade e a falta de suporte prático nos documentos.

No que se refere ao distanciamento entre as Políticas e a realidade das práticas foi apontada a descontextualização no que tange à aplicabilidade dos programas e projetos à realidade das escolas, principalmente no que concerne à escassez de materiais e às condições socioeconômicas e culturais dos alunos da comunidade escolar. Na sequência, exemplo de relato:

Todos os programas e todas as leis visam o bem estar de todos. Eu vejo
assim. Mas para você adaptar aquela lei à realidade tem um caminho a
seguir. Muitos são distanciados da realidade. Porque eles fazem as
pesquisas, mas tem hoje a diversidade de vida, vida não, de atuação na
vida é tão diferente, eu acho que às vezes eles direcionam para um
caminho muito estanque e dentro da sala de aula ela é muito mais diversa.
(E1)
Eu acho que as coisas estão muito bonitas no papel, mas a realidade é
outra. Se pensa em coisas de outras culturas e realidades para fazer os
manuais e programas, mas nossa realidade é outra. (E10)

Verifica-se nos relatos de E1 e E10 que estes professores apresentam conhecimento das Políticas, dado o embasamento crítico para justificar a compreensão de que elas não contribuem com a realidade das práticas. Compreende-se que estes resultados oferecem possíveis perspectivas para a aproximação das Políticas com a realidade das práticas. Assim, revela-se a necessidade de adaptação das Políticas frente as diferentes realidades e culturas, de modo a favorecer a superação do engessamento e uniformização de como estão colocadas na atualidade.

Do mesmo modo, sugere-se que, para além da inclusão de necessidades específicas das instituições e comunidades locais, que os adolescentes, bem como os demais atores envolvidos nas práticas de Educação Sexual, participem e contribuam na construção das propostas.

Ainda com relação à percepção sobre fragilidades das Políticas para as práticas, verificou-se nos resultados a percepção de que os documentos públicos devem oferecer mais subsídios para nortear as práticas realizadas junto aos adolescentes, conforme se observa nos depoimentos a seguir, de E7, "[os] PCNs citam as coisas, mas não traz assim, como a gente deve estar trabalhando, fazendo

R. Inter. Interdisc. INTERthesis, Florianópolis, v.14, n.3, p. 69-87 Set.-Dez. 2017 
[...]", e de E6, "[os] nossos PCNs, os currículos estão lá. De uma forma escrita até em negritos, mas que, só diz: Sexualidade. Ele não destrincha."

Evidencia-se a necessidade de um suporte mais prático para embasar as práticas desenvolvidas. Embora as Políticas contribuam com conteúdos, predominantemente teóricos, revelam-se lacunas no que tange à instrumentalização dos profissionais para a aplicação e efetivação nas ações.

Reconhece-se, portanto, que desafios permanecem no que tange à efetiva aplicação das Políticas na realidade cotidiana, tanto relacionado à inclusão de temáticas específicas nos currículos e nas práticas de Educação Sexual, quanto vinculado à adequação das Políticas às múltiplas realidades sociais e culturais.

Apesar das fragilidades apontadas sobre as Políticas Públicas da Educação no contexto da sexualidade, elas também foram destacadas como documentos que legitimam a execução da Educação Sexual nas escolas, conforme o relato de E4:

[...] parece que a legislação veio assim fortalecer essa questão de realmente tratar o assunto, mesmo, não deixar de lado e com seriedade. Eu acho que nos últimos anos aconteceu isso, mas tem muito a ser feito, porque a gente está longe do ideal. (E4)

No que se refere às Políticas garantirem a execução das práticas, dado seu aspecto legal, foi evidenciada a sensação de proteção, por parte dos professores frente às possíveis resistências das famílias sobre as práticas de Educação Sexual com os adolescentes, conforme se observa no depoimento a seguir:

Os documentos ajudam assim, na liberação para trabalhar. Quando eu comecei, era proibido falar sobre o assunto. A diretora falava que tinha que pedir autorização para os pais, caso algum pai reclamasse eu poderia até responder processo, mas graças a Deus nunca aconteceu, mas com o ECA acaba vindo assim, que a escola é obrigada a falar sobre o assunto...então os Programas e Projetos vem para facilitar a gente ter liberdade de falar sobre o assunto, de trabalhar. (E7)

Questiona-se se as Políticas Públicas realmente protegem as escolas frente a possíveis movimentos de resistências das famílias para a execução da Educação Sexual nas escolas. Sobre esta questão, para além do respaldo legal que os documentos oferecem, sugere-se uma maior aproximação e parceria das famílias com as escolas, de forma que seja aprofundada a compreensão das atribuições da escola, bem como da importância da Educação Sexual e demais atividades pedagógicas desenvolvidas (MOIZÉS; BUENO, 2010).

No tocante às Políticas de Educação vinculadas à Educação Sexual apresentadas nos resultados, considera-se que a aproximação e o conhecimento

R. Inter. Interdisc. INTERthesis, Florianópolis, v.14, n.3, p. 69-87 Set.-Dez. 2017 
mais aprofundados desses documentos, por parte dos profissionais que executam as práticas mostram-se salutares para uma avaliação mais crítica sobre as contribuições e avanços dessas Políticas no âmbito da Educação Sexual no espaço escolar. Esta sugestão está relacionada tanto ao fato de que a maior apropriação dos conteúdos oferecerá subsídios mais concretos para as práticas, quanto à importância de se conhecer os documentos em sua totalidade para a identificação e crítica sobre lacunas existentes e necessidades de avanços nas Políticas Públicas.

\subsection{SETOR DA SAÚDE}

No setor da Saúde, com relação às contribuições das Políticas Públicas, foi identificada uma compreensão de que os documentos, programas e projetos oferecem embasamento e respaldo para as práticas. No que se refere ao embasamento, verificou-se que os subsídios teóricos, contidos nos manuais, embasam as ações de cuidado à saúde sexual e reprodutiva dos adolescentes, conforme o depoimento:

[...] muito importante porque dá base para a gente, tanto científica quanto para a gente estar lidando, do conhecimento que a gente tem. Eu acho que é uma troca, teórico e prática. (S4)

De acordo com os resultados, para os profissionais do setor da Saúde há uma ressonância positiva advinda destas Políticas, de forma que consideram que estas oferecerem subsídios para as práticas e configuram-se como ferramentas para as ações de cuidado dos adolescentes, no sentido teórico e prático.

Quanto a outro aspecto das Políticas Públicas, identificados pelos participantes como contribuições, destacou-se a dimensão legal das Políticas, que tanto legitimam e garantem a execução da Educação Sexual para os adolescentes quanto protegem os profissionais de possíveis resistências das famílias. Neste caso, a vacinação recente para a prevenção do vírus Human Papiloma Virus (HPV) (BRASIL, 2002) foi utilizada como exemplo, uma vez que algumas famílias demonstraram resistência e, para estarem legalmente respaldados, os profissionais da Saúde revisitaram documentos públicos vinculados aos direitos dos adolescentes, como se verifica no relato:

[...] outro dia coma vacina do HPV, a gente ficou com a questão, "vai fazer sozinho, não vai fazer sozinho?" e aí assim, é de direito, está lá no Estatuto, eu não gostaria que minha filha saísse para a escola e fosse vacinada, eu 
não gostaria, mas no Estatuto está dizendo que se ela for sozinha procurar o serviço de saúde é para fazer então eu acho que isso que tem clareza,dá um norte para a prática sem dúvida. (S3)

Eles respaldam o trabalho da gente. Tanto a questão técnica, que eles te dão uma orientação técnica, quanto de respaldo mesmo, porque é aquela coisa, o ECA está aí, você pode pegar o adolescente, ontem aliás foi uma discussão em uma reunião de vacina, que vai vacinar adolescente do HPV, mais da metade da reunião foi "vai vacinar adolescente que chegar sozinho na Unidade?" E se tiver algum problema? Aí é assim, o ECA respalda. Esses documentos são importantes para isso. (S5)

De acordo com os resultados, há uma preocupação com o modo das famílias compreenderem a abordagem de práticas vinculadas à Educação Sexual com os adolescentes nas Unidades de Saúde da Família. Sabe-se que a saúde é um direito garantido por lei a todos os cidadãos, desde a Constituição de 1988 (BRASIL, 1988).

Do mesmo modo, o ECA trata de uma Política posterior que reforça a legitimidade do direito ao acesso à saúde, no qual a criança e o adolescente são também destacados como prioridade absoluta (BRASIL, 1990b). Ou seja, de acordo com os resultados, evidencia-se a fundamental importância das Políticas, no entanto, aponta-se a necessidade de avanços, por exemplo, no que se refere à necessidade de superar as resistências e preocupações na relação com as famílias.

Embora existam tantas conquistas das Políticas, os resultados do presente estudo evidenciam, em conformidade com a literatura, que muitas famílias ainda demonstram valores morais significativamente conservadores e negativos sobre a sexualidade e acabam por privar os filhos de orientação (GONÇALVEZ; FALEIRO; MALAFAIA, 2013). Sugere-se que o esclarecimento dessas famílias sobre as questões legais nos espaços de educação em saúde nas Unidades pode ser uma importante estratégia no processo de superação de resistências e construção de parcerias entre o serviço e as famílias.

Com relaçãoàs fragilidades, foram identificados diversos fatores que justificavam os limites relacionados às Políticas Públicas. A falta de suporte mais prático, em função da predominância de conteúdos teóricos provenientes dos documentos, programas e projetos demonstrou-se como um aspecto negativo. Retoma-se um dos desafios para o cotidiano das práticas, a necessidade de capacitação em sexualidade na adolescência, mais especificamente sobre estratégias de abordagem junto a esta população, conforme se verifica no relato:

Eu acho, para mim não está contribuindo. É uma coisa teórica, sempre a mesma coisa e eu já queria mais dinâmicas, coisas mais...e aquela coisa é

R. Inter. Interdisc. INTERthesis, Florianópolis, v.14, n.3, p. 69-87 Set.-Dez. 2017 
muito difícil "Ah, eu vou montar um grupo de adolescentes, de gestantes". Eu não consigo, elas não vêm. Como é que eu faço para conseguir fazer essas pessoas virem? Não sei, alguma coisa que ajudasse nessa parte. (S1)

Foi identificada também a ausência de documentos públicos que deveriam ser utilizados no cotidiano das práticas de cuidado com os adolescentes, com destaque à Caderneta do Adolescente do Ministério da Saúde (BRASIL, 2009b). De acordo com os profissionais de saúde, este documento, embora seja relevante e possa contribuir positivamente para as práticas com os adolescentes, na realidade não é utilizado ou não chega até as Unidades de Saúde da Família em quantidade suficiente, conforme se observa no depoimento:

Eu acho que se fossem usados, como eles vieram para a gente, veio
explicando, veio a cadernetinha bonitinha, se fossem realmente utilizados,
eu acho que ajudaria muito, porque tem todas as informações do
adolescente ali. Vacinas têm questões de dúvidas deles, tem a questão de
sexualidade, tem a questão de doenças que tem na faixa deles,
crescimento, essas coisas. Ele teria o acesso desse documento. Todos os
dados dele estariam nele. Ajudaria bastante em consulta e tudo e até na
própria vida dele, só que não é usado. (S10)

Seria muito bom se eles fossem usados. Hoje, contribuição nenhuma, porque eles não existem. Se você me pedir uma caderneta de adolescente eu não tenho para te dar. Eu a conheço porque ela foi apresentada num evento, no qual cada Unidade ganhou meia dúzia e nunca mais veio. Nossa, um material muito legal, com ilustrações, fotos, com desenhos, que daria para abordar muito, conversar muito com o adolescente e eu acho que seria abrir uma porta mesmo. (S8)

Retoma-se os distanciamentos entre o que se prevê nas Políticas, programas e documentos públicos e a implementação e efetivação na realidade.

Observa-se que nas cadernetas as questões relativas à sexualidade abordam conteúdos importantes sobre prevenção à saúde sexual e reprodutiva na adolescência, porém, aspectos afetivos e sociais, como relacionamentos, desejos, dentre outros, não aparecem incluídas questões relativas à diversidade sexual. Destaca-se que, em uma perspectiva de integralidade do sujeito, a orientação sexual é parte legítima e integrante dos sujeitos e, portanto, deveria ser considerada e abordada com os adolescentes.

Verificou-se também como fragilidade a necessidade de os profissionais do setor da Saúde e de outros setores terem maior aproximação e entendimento sobre os programas e projetos advindos do Ministério da Saúde conforme pode ser verificado no relato: 
Eu acho que eles contribuem só porque é uma obrigação, obriga a fazer. Eu acho que é uma coisa colocada, mesmo o PSE. Eu acho que é uma coisa da gente ir atrás, de como se faz. Por que assim, principalmente na atual gestão a gente faz o trabalho mais sozinha mesmo. Não tem muito respaldo, muito apoio. É uma coisa mais da gente ir atrás mesmo, se informar e colocar na prática porque a gente vai ser cobrado. Respaldo teórico traz, mas você ter o respaldo teórico e colocá-lo na prática é bem diferente. Acho que até muita coisa que está no teórico édiferente da prática. (S9)

Aponta-se que o PSE depende da inserção das ações previstas por este programa nas rotinas dos serviços de saúde e educação (FERREIRA et al., 2014). Do mesmo modo, em consonância com os resultados, o entendimento da proposta deste programa, bem como as maneiras de executá-la, por parte dos profissionais e serviços, mostra-se imprescindível (FERREIRA et al., 2014).

Ressalta-se que tanto na execução do PSE, como demais programas e projetos intersetoriais, a gestão municipal dos setores da Saúde e da Educação, tem um papel fundamental, tanto no sentido de apoio, como no monitoramento e avaliação do Programa. Esta participação da gestão, bem como o envolvimento dos dois setores, se mostra salutar na realização e concretização de bons resultados destas iniciativas que buscam garantir o cuidado integral dos adolescentes.

\section{CONSIDERAÇÕES FINAIS}

Observa-se que em ambos os setores foram identificadas, nos conteúdos dos relatos, contribuições e fragilidades relativas às Políticas Públicas. Tanto no setor da Educação quanto no setor da Saúde, como contribuições das Políticas, foi verificado que as mesmas oferecem subsídios para as ações. Do mesmo modo, em ambos os setores evidenciou-se que as Políticas oferecem também como contribuição o respaldo legal para a execução das práticas. A preocupação com os pais e familiares é evidenciada, de modo que o respaldo legal para a abordagem da Educação Sexual aparece como um possível 'escudo protetor'.

Quanto às fragilidades das Políticas Públicas, nos resultados advindos do setor da Educação foi apontada a descontextualização das propostas, no sentido de engessamento dos projetos e da falta de recursos para desenvolver as atividades previstas, bem como a não efetivação da transversalidade e a interdisciplinaridade,

preconizadas pelos $\mathrm{PCN}$. Discutiu-se que embora a transversalidade e a interdisciplinaridade estejam previstas nos PCN desde 1997, em conformidade com 
a literatura, os resultados evidenciam que as práticas permanecem predominantemente vinculadas às disciplinas de Ciências.

Sobre as fragilidades das Políticas Públicas evidenciadas pelo setor da Saúde, foi identificada a necessidade de estas oferecerem mais subsídios práticos, bem como a dificuldade que encontram para acessar materiais provenientes das Políticas. Do mesmo modo, evidenciou-se como fragilidade a necessidade dos profissionais terem maior conhecimento e domínio dos documentos públicos que embasam ou deveriam embasar as ações.

Considera-se que a questão do desconhecimento dos profissionais merece destaque. A maioria das Políticas Públicas vinculadas à Educação Sexual, especialmente provenientes do Ministério da Saúde são elaboradas para oferecer embasamento para as práticas (SFAIR, 2012). No entanto, de acordo com estes resultados, evidencia-se uma possível falta de conhecimento e/ou desuso dos documentos públicos por parte dos profissionais.

Desse modo, sugere-se que espaços de educação permanente, previstos pelo Sistema Único de Saúde (SUS) (BRASIL, 2009c), foquem também na revisitação de documentos públicos que devem balizar as práticas nos serviços.

Compreende-se que este estudo avança ao revelar as percepções dos profissionais dos setores da Saúde e da Educação com relação às Políticas Públicas vinculadas à adolescência e à sexualidade. Considera-se que estas informações, advindas dos atores que atuam nos serviços sobre as Políticas Públicas, devem balizar as práticas e contribuem para a identificação de potencialidades e lacunas que podem ser utilizadas como ferramentas para a avaliação e elaboração das Políticas. Nesta direção, somam-se elementos para a concretização e implementação do que está previsto pelas Políticas Públicas na realidade das práticas vinculadas à Educação Sexual nos serviços de educação e saúde. 


\title{
PUBLIC POLICIES AND SEX EDUCATION: PERCEPTIONS OF HEALTH AND EDUCATION PROFESSIONALS
}

\begin{abstract}
:
Actions for the promotion, protection and recovery of integral health aimed at adolescence sexuality are advocated by several Public Policies; however, for the advancement of actions in this field, challenges and limits have been investigated. The objective of this research was to identify, from the point of view of professionals included in public services of Health and Education, the advances and challenges implied in Public Policies related to Adolescence and Sexual Education. It was a qualitative study, in which 20 professionals from the public health and education services of a large municipality in the interior of São Paulo were interviewed. The results of both sectors revealed the perception that Public Policies linked to Sexual Education and adolescence bring contributions to practices, although they present frailties. As contributions, the following stand out: the legal subsidies and the support for the practices' execution. The weaknesses pointed out were: the decontextualized proposals, lack of practical support and lack of policies' knowledge by the professionals. The information seized contributes to the identification of potentialities and gaps that can be used as tools for policy evaluation and elaboration. In this direction, it was added elements for the implementation of what is foreseen by the public policies in the reality of the Sexual Education practices.
\end{abstract}

Keywords: Public Policies. Collective Health. Sexuality. Sexual Education. Adolescents.

\section{POLÍTICAS PÚBLICAS Y EDUCACIÓN SEXUAL: PERCEPCIONES DE PROFESIONALES DE LA SALUD Y LA EDUCACIÓN}

\section{Resumen:}

Acciones de promoción, protección y recuperación de la salud integral direccionada a la sexualidad en la adolescencia son recomendadas por diversas Políticas Públicas, sin embargo, a fin de promover acciones en este campo se han investigado retos y límites. Esta investigación tuvo como objetivo identificar, desde la perspectiva de los profesionales de los servicios públicos de Salud y Educación, los avances y desafíos incluidos en las Políticas Públicas relacionadas a la adolescencia y a la Educación Sexual. Este fue un estudio de enfoque cualitativo, en el que se encuestó a 20 profesionales del servicio público de Salud y de Educación de un municipio de gran porte del interior de São Paulo. Los resultados de ambos sectores revelaron la percepción de que las políticas relacionadas a la Educación Sexual y la adolescencia contribuyen con estas prácticas, aunque señalen algunas fragilidades. Como contribuciones se destacan: los subsidios y los apoyos legales para la ejecución de las prácticas. Las fragilidades identificadas fueron: propuestas descontextualizadas, falta de apoyo práctico y desconocimiento de los profesionales con respecto a las políticas. Las informaciones retenidas contribuyen para la identificación de fortalezas y debilidades que se pueden utilizar como herramientas para evaluación y elaboración de las políticas. En esta dirección se suman elementos para llevar a cabo lo dispuesto en las políticas públicas y en la realidad de las prácticas de Educación Sexual.

Palabras clave: Políticas Públicas. Salud Colectiva. Sexualidad. Educación Sexual. Adolescentes. 


\section{REFERÊNCIAS}

ALTMANN, H. A sexualidade adolescente como foco de investimento político-social. Educação em Revista. Belo Horizonte, n. 46. p. 287-310, 2007.Disponível em http://www.scielo.br/pdf/edur/n46/a12n46.pdf

BARDIN, L. Análise de Conteúdo. Lisboa, Portugal: Edições 70, LDA, 2009. 279p.

BRASIL. Constituição da República Federativa do Brasil: promulgada em 5 de outubro de 1988. Brasília, Centro Gráfico, 1988, 929 p.

$\frac{1}{1990 b .}$. Estatuto da Criança e do Adolescente. Lei n 8.069. Cortez, São Paulo, Ministério da Saúde. Programa Saúde do Adolescente. Bases Programáticas. $2^{\circ}$ ed. Brasília, DF, 1996a, 32 p.

Lei $\mathbf{n}^{\circ} \mathbf{9 . 3 9 4}$, de 20 de dezembro de 1996. Estabelece as diretrizes e bases da educação nacional. Brasília, 1996b. Disponível em: <http://www.planalto.gov.br/ccivil 03/leis/L9394.htm > Acesso em: 12 de mai. 2013.

Lei $n^{\circ}$ 9.263, de 12 de janeiro de 1996. Regula o $\S 7^{\circ}$ do art. 226 da Constituição Federal, que trata do planejamento familiar, estabelece penalidades e dá outras providências. Brasília, DF, 1996c. Disponível em <http://www.planalto.gov.br/ccivil 03/leis/l9263.htm> Acesso em: 21 jul. 2014.

\section{Secretaria de Educação Fundamental. Parâmetros curriculares}

nacionais: apresentação dos temas transversais. Brasília: MEC/SEF, 1997. 146 p.

. Ministério da Saúde. Secretaria de Atenção à Saúde. Departamento de Ações Programáticas e Estratégicas. Marco Teórico e Referencial Saúde Sexual e Saúde Reprodutiva de Adolescentes e Jovens. Série B. Textos Básicos de Saúde. Brasília, 2007a. 56 p.

- Ministério da Saúde. Secretaria de Atenção à Saúde. Departamento de Ações Programáticas Estratégicas. Área Técnica de Saúde do Adolescente e do Jovem. Política nacional de atenção integral à saúde de adolescentes e jovens. Brasília, DF, 2007b.

. Ministério da Saúde. Ministério da Educação. Programa Saúde nas Escolas, Brasília, 2007c. 
Ministério da Educação. Diversidade Sexual na Educação:

problematizações sobre a homofobia nas escolas. Brasília, 2009a. 442p.

. Ministério da Saúde. Caderneta de Saúde do Adolescente. Brasília, DF, 2009b. Disponível em:

$<$ http://bvsms.saude.gov.br/bvs/publicacoes/caderneta saude adolescente menina. pdf>. Acesso em: 4 jun. 2014.

. Ministério da Saúde. Secretaria de Gestão do Trabalho e da Educação na Saúde. Departamento de Gestão da Educação em Saúde. Política Nacional de Educação Permanente em Saúde. Série B. Textos Básicos de Saúde. Brasília, 2009c. 64 p.

. Ministério da Saúde. Saúde Sexual e Reprodutiva de adolescentes e jovens- Caderno de Atenção Básica, Brasília, 2013.

Ministério da Saúde. Secretaria Executiva. Programa de Humanização do parto. Brasília, DF, 2002. Disponível em <http://bvsms.saude.gov.br/bvs/publicacoes/parto.pdf>. Acesso em: 4 jul. 2014.

FERREIRA, I. R. C.; MOYSÉS, S. J.; FRANÇA, B. H. S; MOYSÉS, S. T. Avaliação da intersetorialidade no Programa Saúde na Escola. Manual metodológico. Curitiba: Champagnat (PUC-PR), 2014.

FONTES, M. Ilustrações do Silêncio e da Negação: a ausência de imagens da diversidade sexual em livros didáticos. Revista Psicologia Política, São Paulo, v.8, n.16, p. 363-378, jul. /dez. 2008.

GOMES, M. R. O; VIEIRA, N. Saúde e Prevenção nas escolas: promovendo a educação em sexualidade no Brasil. Revista tempus Acta em Saúde Coletiva, v. 4, n.2, 2010. Disponível em:

http://www.tempusactas.unb.br/index.php/tempus/article/viewFile/798/786

Acesso em: 14 abr. 2013.

GONÇALVEZ, R. C.; FALEIRO, J. H.; MALAFAIA, G. Educação Sexual no contexto familiar e escolar: impasses e desafios. Holos, Ano 29, v. 5, p. 251-263, 2013.

Disponível em: http://www2.ifrn.edu.br/ojs/index.php/HOLOS/article/viewFile/784/741 Acesso em: 15 jul. 2014. 
MOIZÉS, J. S.; BUENO, S. M. V. Compreensão sobre sexualidade e sexo nas escolas segundo professores do ensino fundamental. Revista da Escola de Enfermagem da USP, São Paulo, v.44, n.1, p.205-212, mar. 2010.

NARDI, H. C. O Estatuto da diversidade sexual nas Políticas de Educação no Brasil e na França: a comparação como ferramenta de desnaturalização do cotidiano de pesquisa.Psicologia e Sociedade, Porto Alegre, v.20, n.spe, 2008. p. 12-23. Disponível em: http://www.scielo.br/pdf/psoc/v20nspe/v20nspea04.pdf Acesso em 20 abr. 2014.

NARDI, H. C.; QUARTIERO, E. Educando para a diversidade: desafiando a moral sexual e construindo estratégias de combate à discriminação no cotidiano escola. Sexualidad, Salud y Sociedad, n.11, p.59-87, ago. /2012.

PAIVA, $V$ et al. Idade e uso de preservativo na iniciação sexual de adolescentes brasileiros. Revista de Saúde Pública, v. 42, n. 1, p. 45-53, 2008.

RIOS, R.; SANTOS, W. Diversidade sexual, educação e sociedade: reflexões a partir do Programa Nacional do Livro Didático. Psicologia Política, São Paulo, v. 8, n. 16, p. 325-344, dez. 2008.

SFAIR, S.C. Educação Sexual para adolescentes e jovens: o que preveem os documentos públicos nos níveis Federal e Estadual em São Paulo. 2012. 113 f. Dissertação de Mestrado em Terapia Ocupacional- Programa de Pós-Graduação em Terapia Ocupacional, Universidade Federal de São Carlos, São Carlos, 2012.

SILVA, D. P. M. Gênero e sexualidade nos PCNs: uma proposta desconhecida. In: REUNIÃO ANUAL DA ASSOCIAÇÃO NACIONAL DE PÓS-GRADUAÇÃO E PESQUISA EM EDUCAÇÃO, ANAIS, ANPED, Caxambu, 2007. Disponível em: $<$ http://30reuniao.anped.org.br/trabalhos/GT23-2871--Int.pdf >. Acesso em: 30 ago. 2014.

SILVA, R. C. P.; MEGID-NETO, J. Formação de Professores e Educadores para abordagem da educação sexual na escola: o que mostram as pesquisas. Ciência e Educação, Bauru, v.12, n.2, p. 185-197, mai/ago. 2006.

\section{Artigo:}

Recebido em 12 de Dezembro de 2016.

Aceito em 15 de Agosto de 2017. 